\title{
Clinical evaluation of a novel herbal dental cream in plaque formation: a double-blind, randomized, controlled clinical trial
}

This article was published in the following Dove Press journal:

Journal of Experimental Pharmacology

26 July 2010

Number of times this article has been viewed

\author{
Sunita Amrutesh' \\ J Malini² \\ Prakash S Tandur ${ }^{3}$ \\ Pralhad S Patki ${ }^{4}$ \\ 'Department of Oral Medicine \\ and Radiology, ${ }^{2}$ Department of \\ Microbiology, ${ }^{3}$ Department of Oral \\ and Maxillofacial Surgery, K.L.E. \\ College of Dental Sciences and \\ Hospital, Bangalore, India; ${ }^{4}$ Medical \\ Services and Clinical Trials, R\&D \\ Center, The Himalaya Drug Company, \\ Bangalore, India
}

Background: The aim of this study was to evaluate the efficacy and safety of herbal dental cream in comparison to fluoride dental cream.

Objectives: Clinical evaluation of a novel herbal dental cream in plaque formation: a double-blind, randomized, controlled clinical trial.

Methods: One hundred and two patients with established dental plaque were randomly assigned to either herbal dental group or fluoride dental group for six weeks in a double-blind design. Improvement in plaque index, oral hygiene status, bleeding index, and gingival index was evaluated in these patients along with microbiological study.

Results: Results indicated a significant reduction in plaque index, gingival index, oral hygiene index, and microbial growth in both groups. Difference between the groups was not significant. There was no significant change in bleeding index. No adverse events were reported and both the dental creams were well tolerated.

Conclusion: The finding of this preliminary study indicates that herbal dental cream is as safe and effective as fluoride dental cream, but not superior to it.

Keywords: dental plaque, herbal, microbial growth

\section{Introduction}

Dental caries remains the most important dental health problem in developing countries. In the Indian subcontinent, the prevalence of dental caries is reported to be about $50 \%-60 \%{ }^{1}$ Dental plaque, one of the etiological agents of caries and periodontal disease, can be removed or at least decreased by the simple systematic use of toothbrushes and dental cream. Yet there is need for lower cost and good acceptance in dental homecare measures in Asian countries. Dental plaque is a living, organized community of microorganisms comprising various species, which are embedded in an extracellular matrix. The plaque may grow bigger with cumulative addition of anaerobic microorganisms. Bacteria colonizing the teeth in the initial phase of dental caries and periodontal disease are now well established. ${ }^{2}$ Removal and minimization of plaque may halt the dental deterioration, and hence is essential for oral hygiene. This can be achieved by regular brushing of teeth, especially by individual motivation. ${ }^{3,4} \mathrm{~A}$ number of anti-plaque agents in dental creams have been formulated and evaluated for the management of dental plaque., ${ }^{4,5}$ Fluorides are abundantly used in dental creams and mouthwashes. They are described to inhibit carbohydrate utilization by oral microorganisms by blocking enzymes involved in the bacterial glycolytic pathway. ${ }^{6}$ Synthetic dentifrices commonly used contain chemical agents, which are known to produce harmful side effects with prolonged 
use. Hence, herbal dental products are becoming popular amongst general public. Ayurveda, the ancient Indian system of medicine, advises different methods for regular practice to maintain optimal dental health. A number of herbs have been recommended to help and maintain dental health. ${ }^{7}$ Recently, a herbal dental cream has been introduced in clinical practice, which consists of powders of Ajamoda satva, Vaikranta bhasma, and Azadirachta indica; and extracts of Zanthoxylum alatum, Punica granatum, Acacia arabica, Vitex negundo, Embelia ribes, and Triphala - all recommended in Ayurveda for dental health. The purpose of the present study was to compare the efficacy and safety of this novel herbal dental cream with a fluoride dental cream in a double-blind, randomized fashion, in patients with established dental plaque.

\section{Material and methods Subjects}

This prospective study included 102 patients who were attending the outpatient department of Oral Medicine and Radiology, K.L.E. College of Dental Sciences and Hospital, Bangalore, India, during February and March 2006. Sample size was determined by a power analysis based on mean and standard deviation values for periodontal indices presented in a previous study. ${ }^{8}$ Patients who agreed to participate signed an informed consent form before the study and they were detailed the contents of the entire study. Approval from the Institutional Ethics Committee at K.L.E. College of Dental Sciences and Hospital, Bangalore, was obtained before the study began.

\section{Procedure}

Adult patients of both sexes attending the outpatient department of Oral Medicine and Radiology, K.L.E. College of Dental Sciences and Hospital, Bangalore, India, were evaluated for dental caries during February and March 2006. Patients with a minimum 20 permanent dentiture, having dental plaque, and general good health were included in the study. Pregnant women and patients with severe oral pathology or orthodontic appliances or history of allergy to any medication were excluded from the study. Also, patients with cardiovascular, renal, and liver diseases were excluded. The patients were randomized using Latin square ${ }^{9}$ to receive either herbal dental cream or fluoride dental cream in a double-blind design.

Patients in the herbal dental group received a dental cream tube containing $150 \mathrm{~g}$ of herbal ingredients (fluoride content $500 \mathrm{ppm}$ as calcium fluoride from Vaikranta Bhasma with no triclosan), whereas patients in the fluoride dental cream group received an identical dental cream tube $(150 \mathrm{~g})$ containing sodium fluoride $(1,450 \mathrm{ppm})$ and triclosan $(0.30 \%)$. The included patients underwent a systematic clinical examination for caries and plaque in a dental setting. The tooth surface was visually examined, and a probe was used only to remove plaque or to confirm or reject visual diagnosis of doubtful lesions. Prior to each evaluation, patients were asked to refrain from brushing 12-14 hours before the evaluation time, so that the plaque removal could be measured at each appointment. Plaque index, ${ }^{10}$ oral hygiene status, ${ }^{11}$ bleeding index, ${ }^{12}$ and gingival index ${ }^{13}$ were recorded during each visit, for six weeks on a weekly basis. The scorers were unaware of the treatment group. They were trained to brush their teeth with respective dental creams and an identical soft brush twice a day, using modified Bass method. ${ }^{14}$ Plaque index was scored on four surfaces (buccal, lingual, mesical, and distal) of six representative teeth $(16,12,24,44,32,36)$. The mean index was calculated by dividing the sum of number from scale by the total number of sites scored within the mouth. Bleeding index was measured by guiding probe through the gingival sulcus in the first and third quadrants from the buccal aspect and in the second and fourth quadrant from the oral aspect. Gingival index was scored on the buccal marginal gingival of the Ramfijord teeth. They were told to refrain from all other oral hygiene measures except the directed ones. Plaque from these patients were subjected to microbiological assay for the growth of Streptococcus mutans and Staphylococcus lugdunensis on Week 0 and at the end of six weeks using sterile plastic toothpicks and placed in $5 \mathrm{~mL}$ of reduced transport fluid. ${ }^{15}$ Patient compliance was monitored using compliance calendars, which were provided to them at the beginning of the study. Adverse effects, if any, were recorded during each visit for a period of six weeks. All the procedures in this study were performed according to the ethical principles established by the Declaration of Helsinki. ${ }^{16}$

\section{Statistical analysis}

Results obtained were analyzed by analysis of variance (ANOVA), followed by Dunnett's post hoc test to determine difference in the parameters of plaque index, oral hygiene status, bleeding index, and gingival index. Fisher's exact test was used to study the reduction in microbial growth.

\section{Results}

All 102 patients, 54 on herbal dental cream and 48 on fluoride dental cream, completed the study and tolerated the dental creams well. The mean age of the patients in the herbal dental cream group was $28.55 \pm 10.2$ years, and $29.65 \pm 11.4$ years in 
Table I Comparative effect of herbal dental cream and fluoride dental cream on plaque index and gingival index

\begin{tabular}{|c|c|c|c|c|c|c|c|c|}
\hline \multirow[t]{2}{*}{ Product } & \multirow[t]{2}{*}{ Parameter } & \multicolumn{7}{|l|}{ Score } \\
\hline & & Week 0 & Week I & Week 2 & Week 3 & Week 4 & Week 5 & Week 6 \\
\hline \multirow{2}{*}{$\begin{array}{l}\text { Herbal dental } \\
\text { cream } \\
(n=54)\end{array}$} & Plaque index & $\mathrm{I} .29 \pm 0.4 \mathrm{I}$ & $1.21 \pm 0.36$ & $\mathrm{I} .1 \mathrm{I} \pm 0.34^{*}$ & $0.95 \pm 0.42^{*}$ & $0.80 \pm 0.35^{*}$ & $0.72 \pm 0.35^{*}$ & $0.68 \pm 0.29 *$ \\
\hline & Gingival index & $1.28 \pm 0.45$ & $1.14 \pm 0.38$ & $0.97 \pm 0.34^{*}$ & $0.94 \pm 0.72^{*}$ & $0.7 \mathrm{I} \pm 0.38^{*}$ & $0.54 \pm 0.30 *$ & $0.55 \pm 0.35^{*}$ \\
\hline \multirow{2}{*}{$\begin{array}{l}\text { Fluoride dental } \\
\text { cream } \\
(n=48)\end{array}$} & Plaque index & $1.19 \pm 0.28$ & $1.08 \pm 0.12^{*}$ & $0.97 \pm 0.22^{*}$ & $0.92 \pm 0.2 I^{*}$ & $0.91 \pm 0.21 *$ & $0.92 \pm 0.18^{*}$ & $0.89 \pm 0.20 *$ \\
\hline & Gingival index & $1.01 \pm 0.23$ & $0.76 \pm 0.25^{*}$ & $0.72 \pm 0.30^{*}$ & $0.63 \pm 0.24^{*}$ & $0.63 \pm 0.24^{*}$ & $0.67 \pm 0.24^{*}$ & $0.64 \pm 0.24^{*}$ \\
\hline
\end{tabular}

Notes: Values represents mean \pm SD. Statistical analysis by repeated measures of ANOVA, followed by Dennett's multiple comparison post hoc test. $* P<0.05$ as compared to respective Week 0 values.

the fluoride dental cream group. There were no dropouts, and both the groups were comparable at baseline regarding dental parameters like plaque index, gingival index, bleeding index, oral hygiene score, and microbial growth. Plaque index and oral hygiene index showed a significant linear decrease from baseline from the third week onwards in both the groups, and it remained so till the end of the study. A similar trend was seen with gingival index, which decreased from a mean score of 1.28 to 0.55 in the herbal dental cream group, and from 1.01 to 0.64 in the fluoride dental cream group (Tables 1 and 2). Before use of herbal dental cream, there were 41 patients who showed presence of Streptococcus mutans in the dental plaque and this was decreased to 22 after treatment. The same trend was also observed in the fluoride dental cream. In the case of Staphylococcus lugdunensis, $80 \%$ patients were devoid of this organism in their dental plaque after treatment with herbal dental cream, whereas $70 \%$ patients treated with fluoride dental cream did not show the presence of this bacterium. There was a significant reduction in the microbial growth of Streptococcus mutans and Staphylococcus lugdunensis at the end of six weeks in both the herbal and fluoride dental cream groups (Figures 1 and 2). Thus, the improvement started from the second week and continued up to the end of the study. There was no significant change in bleeding index in both the groups. However, there was no significant difference between the parameters measured in the two groups. None of the patients showed any adverse effect with either of the dental creams.

\section{Discussion}

Maintenance of good oral hygiene is the key to prevention of dental diseases. The primary etiological factor for dental diseases is dental plaque. The formation of plaque on the teeth is characterized by a progression from a limited number of bacteria to the complex flora of mature dental plaque. This progression involves initial adherence of bacteria to the salivary pellicle and subsequent accumulation by growth. The primary acid-tolerant anaerobic bacteria associated with the plaque are Streptococcus mutans and Staphylococcus lugdunensis. Ultimately, the tooth surface gets coated with a dense, complex microbial community. Of all the methods of plaque removal, brushing of teeth is the most accepted method of oral hygiene. ${ }^{14}$ Brushing of teeth requires a safe and effective cream to help in the removal of dental plaques. The antibacterial activity of the fluoride dental cream is because of the presence of fluoride and triclosan, but studies have shown that prolonged use of fluoride may lead to adverse effects like dental fluorosis, skeletal fluorosis, and destruction of the epithelial layer of intestine. ${ }^{17}$ Using natural medicines to cure various diseases has become an increasing trend. Herbal medicine has made significant contribution to modern medical practice. ${ }^{18}$ Even though studies in animals

Table 2 Comparative effect of herbal dental cream and fluoride dental cream on oral health and bleeding indices

\begin{tabular}{|c|c|c|c|c|c|c|c|c|}
\hline \multirow[t]{2}{*}{ Product } & \multirow[t]{2}{*}{ Parameter } & \multicolumn{7}{|l|}{ Score } \\
\hline & & Week 0 & Week I & Week 2 & Week 3 & Week 4 & Week 5 & Week 6 \\
\hline \multirow{2}{*}{$\begin{array}{l}\text { Herbal dental } \\
\text { cream } \\
(n=54)\end{array}$} & Oral health index & $4.30 \pm 0.50$ & $4.15 \pm 0.80$ & $3.85 \pm 0.20$ & $3.72 \pm 0.15^{*}$ & $3.50 \pm 0.20 *$ & $3.20 \pm 0.30^{*}$ & $3.15 \pm 0.30 *$ \\
\hline & Bleeding index & $2.60 \pm 0.40$ & $2.50 \pm 0.50$ & $2.45 \pm 0.40$ & $2.30 \pm 0.76$ & $2.28 \pm 0.90$ & $2.14 \pm 0.60$ & $2.12 \pm 0.80$ \\
\hline \multirow{2}{*}{$\begin{array}{l}\text { Fluoride dental } \\
\text { cream } \\
(n=48)\end{array}$} & Oral health index & $4.25 \pm 0.30$ & $4.12 \pm 0.20$ & $3.76 \pm 0.14$ & $3.68 \pm 0.25^{*}$ & $3.52 \pm 0.16^{*}$ & $3.12 \pm 0.20 *$ & $3.11 \pm 0.40 *$ \\
\hline & Bleeding index & $2.56 \pm 0.40$ & $2.52 \pm 0.30$ & $2.50 \pm 0.20$ & $2.28 \pm 0.50$ & $2.26 \pm 0.40$ & $2.22 \pm 0.50$ & $2.16 \pm 0.80$ \\
\hline
\end{tabular}

Notes: Values represents mean \pm SD. Statistical analysis by repeated measures of ANOVA, followed by Dunnett's multiple comparison post hoc test. $* P<0.05$ as compared to respective initial (Week 0 ) values. 


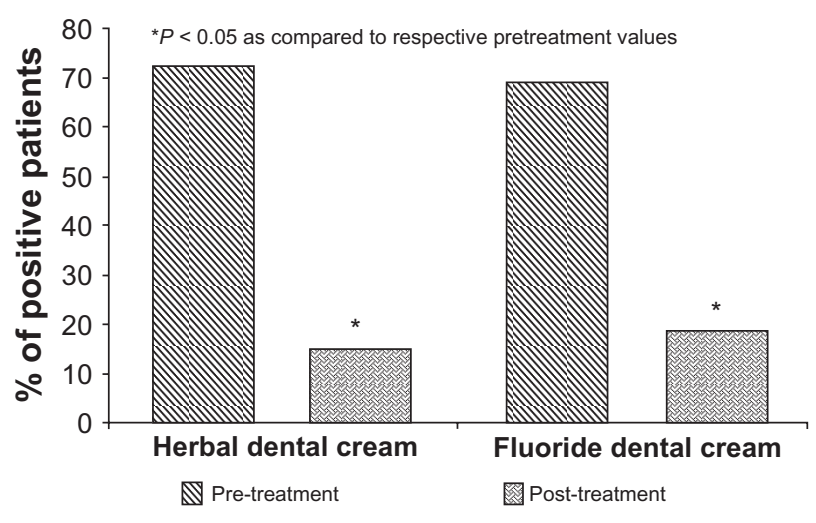

Figure I Comparative effect of herbal dental cream and fluoride dental cream on Streptococcus mutans growth.

and in vitro have shown the antimicrobial properties of several of these herbs, there is no other way of knowing their real clinical effects without a randomized clinical trial. The herbal dental cream studied in the trial appears to be equally effective as the fluoride dental cream, but not superior to it. In addition, it was well tolerated. The polyherbal dental cream contains a number of active ingredients known for their dental pharmacological effects: Azadirachta indica has tetracyclic triterpenoids, which have shown efficacy in plaque management. The herb has also been studied for its anti-caries and antioxidant effects. ${ }^{19-21}$ Punica granatum consists of agents like cyanidin and pelargonidin that have antimicrobial effects and have been studied for their use in periodontitis and halitosis. ${ }^{22}$ Acacia arabica has antimicrobial activity. ${ }^{23}$ Triphala and Embelia ribes have nitric oxide scavenging effects. ${ }^{24,25}$ The antimicrobial activity of the herbs is due to the presence of secondary metabolites such as alkaloids, flavonoids, polyphenols, and lectins. ${ }^{26}$

In addition, fluoride content of Vaikranta bhasma, though low, will add to the antimicrobial activity. Synergistic

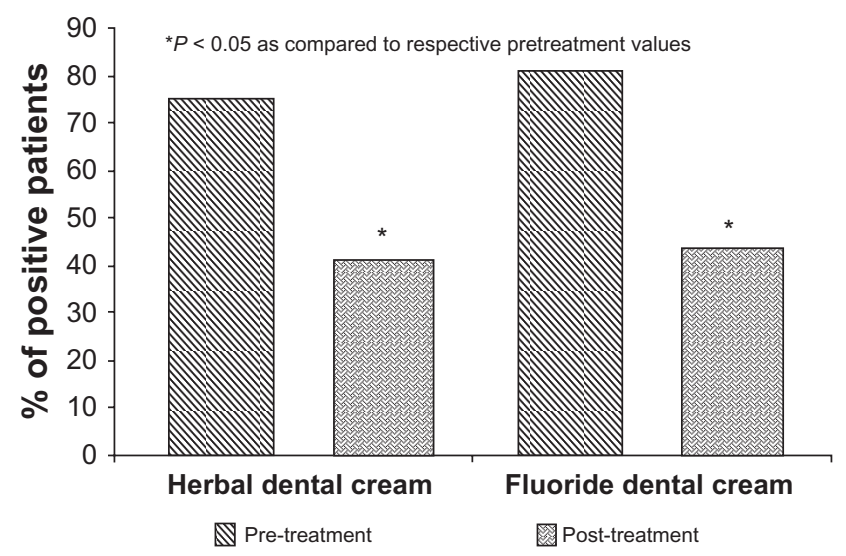

Figure 2 Comparative effect of herbal dental cream and fluoride dental cream on Staphylococcus lugdunensis growth. interactions between the principal components of these herbs are considered to be a vital part of their efficacy. This synergistic activity, however, needs to be established.

\section{Conclusion}

The present study indicates the efficacy and safety of herbal dental cream in the prevention and management of dental plaques, and is as safe and effective as fluoride dental cream, but not superior to it.

\section{Disclosure}

The authors report no conflicts of interest in this work. The Himalaya Drug Company, Bangalore, India is the source of funding for this research.

\section{References}

1. Patro BK, Ravi Kumar B, Goswami A, Mathur VP, Nongkynrih B. Prevalence of dental caries among adults and elderly in an urban resettlement colony of New Delhi. Indian J Dental Res. 2008;19(2): 95-98.

2. Carranza FA Jr. Glickman's Clinical Periodontology. 7th Asian ed. Philadelphia: W.B. Saunders; 1990:342-372, 684-711.

3. Binney A, Addy M, Newcombe RG. The plaque removal effects of single rinsings and brushings. J Periodontol. 1993;64(3):181-185.

4. Batwa M, Bergstrom J, Batwa S, Al-Otaibi MF. The effectiveness of chewing sticks Meswak on plaque removal. Saudi Dental J. 2006;18(3): 125-133.

5. Rolla G, Melsen B. On the mechanism of plaque inhibition by chlorhexidine. J Dent Res. 1975;54:B57-B62.

6. Daniel GA, Stern IB, Everett FG. Periodontics in the tradition of Gottlieb and Orban. 5th ed. St Louis: Mosby; 1979.

7. Amrutesh S. Dentistry and Ayurveda-1. Indian J Dent Res. 2003; 14(1):1-5.

8. Bauroth K, Charles CH, Mankodi SM, Simmons K, Zhao Q, Kumar LD. The efficacy of an essential oil antiseptic mouthrinse vs dental floss in controlling interproximal gingivitis: a comparative study. $J$ Am Dent Assoc. 2003;134(3):359-365.

9. Norton H. The $7 \times 7$ Squares. Ann Eugenics. 1939;9:269-307.

10. Frendsenh A. Mechanical oral hygiene practices. In: Loe H, Kleinman DV, editors. Dental Plaque Control Measures and Oral Hygiene Practices. Washington DC: IRL Press; 1986:93.

11. Greene J, Vermillion JR. Oral hygiene index: a method for classifying oral hygiene index. J Am Dent Assoc. 1960;61:172-177.

12. Babay N, Al Jasser N. Subgingival irrigation effects of chlorhexidine or sanguinarine on gingivitis in orthodontic patients. J Clin Pediatr Dent. 1996;20(3):225-228.

13. Ainamo J, Bay I. Problems and proposals for recording gingivitis and plaque. Int Dent J. 1975;25(4):229-235.

14. Poyato-Ferrera M, Segura-Egea JJ, Bullon-Fernandez P. Comparison of modified Bass technique with normal toothbrushing practices for efficacy in supragingival plaque removal. Int J Dent Hyg. 2003;1(2): 110-114.

15. Limsong J, Benjavongkulchai E, Kuvatanasuchati J. Inhibitory effect of some herbal extracts on adherence of Streptococcus mutans. J Ethnopharmacol. 2004;92(2-3):281-289.

16. World Medical Association Declaration of Helsinki. Ethical Principles of Medical Research Involving Human Subjects: 52nd WMA General Assembly. Washington: WMA; 2002.

17. Susheela AK. Dental fluorosis. In: Susheela AK, editor. A Treatise on Fluorosis. Delhi: Fluorosis Research and Rural Developmental Foundation; 2003:43-57. 
18. Almas K, Dahlan A, Mahmoud A. Propolis as a natural remedy: an update. Saudi Dent J. 2001;13:45-49.

19. Siddiqui BS, Afshan F, Gulzar T, Hanif M. Tetracyclic triterpenoids from the leaves of Azadirachta indica. Phytochemistry. 2004;65(16): 2363-2367.

20. Wolinsky LE, Mania S, Nachnani S, Ling S. The inhibiting effect of aqueous Azadirachta indica (Neem) extract up on bacterial properties influencing in vitro plaque formation. J Dent Res. 1996; $75(2): 816-822$.

21. Pai MR, Acharya LD, Udupa N. Evaluation of antiplaque activity of Azadirachta indica leaf extract gel. J Ethnopharmacol. 2004;90(1): 99-103.

22. Satravaha G, Yotnuengnit P, Booncong P, Sangtherapitikul P. Adjunctive periodontal treatment with Centella asiatica and Punica granatum extracts: a preliminary study. J Int Acad Periodontol. 2003; 5(4):106-107.
23. Clark DT, Gazi MI, Cox SW, Eley BM, Tinsley GF. The effect of Acacia arabica gum on the in vitro growth and protease activities of periodontopathic bacteria. J Clin Periodontol. 1993;20(4):238-243.

24. Chitra M, Devi CS, Sukumar E. Antibacterial activity of embelin. Fitoterapia. 2003;74(4):401-403.

25. Jagetia GC, Rao SK, Baliga MS, S Babu K. The evaluation of nitric oxide scavenging activity of certain herbal formulations in vitro: a preliminary study. Phytother Res. 2004;18(7):561-565.

26. Fatima S, Farooqui AH, Kumar R, Kumar TR, Khaniya SP. Antibacterial activity possessed by medicinal plants used in tooth powder. $J$ Med Arom Pl Sci. 2000;22:187-189.

\section{Publish your work in this journal}

The Journal of Experimental Pharmacology is an international, peerreviewed, open access journal publishing original research, reports, reviews and commentaries on all areas of laboratory and experimental pharmacology. The manuscript management system is completely online and includes a very quick and fair peer-review system.

\section{Dovepress}

Visit http://www.dovepress.com/testimonials.php to read real quotes from published authors. 